\title{
Can Costus afer be used for co-treatment of COVID-19, its symptoms and comorbidities? A novel approach for combating the pandemic and implications for sub-Saharan Africa
}

\author{
Jannat, K. ${ }^{1 \uparrow}$, Hasan, A. ${ }^{1 \uparrow}$, Bondhon, T.A. ${ }^{1 \uparrow}$, Mahboob, T. ${ }^{2}$, Paul, A.K. ${ }^{1}$, Jahan, R. ${ }^{1}$, Nissapatorn, V. ${ }^{2 *}$, \\ Pereira, M.L. ${ }^{3}$, Wiart, C. ${ }^{4}$, Rahmatullah, M. ${ }^{1 *}$
}

${ }^{1}$ Department of Biotechnology \& Genetic Engineering, University of Development Alternative, Lalmatia, Dhaka, Bangladesh

${ }^{2}$ School of Allied Health Sciences, World Union for Herbal Drug Discovery (WUHeDD) and Research Excellence Center for Innovation and Health Products (RECIHP), Walailak University, Nakhon Si Thammarat, Thailand

${ }^{3}$ CICECO-Aveiro Institute of Materials \& Department of Medical Sciences, University of Aveiro, Aveiro, Portugal

${ }^{4}$ School of Pharmacy, University of Nottingham Malaysia Campus, Selangor, Malaysia

IThese authors contributed equally to this work

*Corresponding author: nissapat@gmail.com; rahamatm@hotmail.com

\section{ARTICLE HISTORY}

Received: 9 June 2021

Revised: 13 November 2021

Accepted: 13 November 2021

Published: 31 December 2021

\begin{abstract}
Despite the huge loss of lives and massive disruption of the world economy by the COVID-19 pandemic caused by SARS-CoV-2, scientists are yet to come out with an effective therapeutic against this viral disease. Several vaccines have obtained 'emergency approval', but difficulties are being faced in the even distribution of vaccines amongst high- and lowincome countries. On top of it, comorbidities associated with COVID-19 like diabetes, hypertension and malaria can seriously impede the treatment of the main disease, thus increasing the fatality rate. This is more so in the context of sub-Saharan African and south Asian countries. Our objective was to demonstrate that a single plant containing different phytoconstituents may be used for treatment of COVID-19 and comorbidities. Towards initial selection of a plant, existing scientific literature was scanned for reported relevant traditional uses, phytochemicals and pharmacological activities of a number of plants and their phytoconstituents pertaining to treatment of COVID-19 symptoms and comorbidities. Molecular docking studies were then performed with phytochemicals of the selected plant and SARS-CoV-2 components - Mpro, and spike protein receptor binding domain and hACE2 interface using AutoDock Vina. We showed that crude extracts of an indigenous African plant, Costus afer having traditional antidiabetic and antimalarial uses, has phytochemicals with high binding affinities for Mpro, and/or spike protein receptor binding domain and hACE2 interface; the various phytochemicals with predicted high binding energies include aferoside $C$, dibutyl phthalate, nerolidol, suginal, and \pm -terpinene, making them potential therapeutics for COVID-19. The results suggest that crude extracts and phytochemicals of $C$. afer can function as a treatment modality for COVID-19 and comorbidities like especially diabetes and malaria.
\end{abstract}

Keywords: Costus afer; COVID-19; SARS-CoV-2; molecular docking; Aferoside C.

\section{INTRODUCTION}

The coronavirus pandemic caused by the Severe Acute Respiratory Syndrome Corona Virus-2 (SARS-CoV-2) has now caused considerable disruptions in the world economy and the world population. As of September 2, 2021 the virus has infected $219,291,026$ persons and caused the deaths of 4,545,613 people (https://www.worldometers.info/ coronavirus/). COVID-19 has no available allopathic drugs. Several vaccines have obtained emergency approvals, but it will be a daunting task to vaccinate the world's current population of 7.8 billion, and maintaining vaccine efficacy against quite rapidly emerging new variant strains of the virus.

Although till now, COVID-19 (the disease caused by SARSCoV-2) cases had been low in Africa, the continent and particularly the sub-Saharan countries along with South Africa are now witnessing a surge in COVID-19 cases, which might dramatically impact the continent considering that most countries (including most sub-Saharan countries) are 
economically under-developed and may be ill-equipped to deal with COVID-19 diagnostics and treatment (Nuwagira \& Muzoora, 2020). On top of COVID-19, sub-Saharan African countries suffer from a number of diseases (comorbidities) like malaria, human immunodeficiency virus (HIV), tuberculosis (TB), cholera, and Ebola (Orish, 2015), and noninfectious diseases like diabetes (International Diabetes Federation, 2017), which can complicate COVID-19 treatment and increase the number of fatalities.

Leaving aside other disorders, sub-Saharan African (SSAn) countries may have to cope with three epidemiological disorders at the same time, which disorders are syndemic in the form of COVID-19 (and its symptoms), malaria, and diabetes. No single allopathic medicine can deal with these three disorders (and these disorders-induced secondary complications) by itself. However, plants with their diverse array of phytochemicals can form a viable substitute.

The African continent contains possibly about 35,000 floral species (Couvreur, 2015) and a number of medicinal plants are used in the various African traditional medicinal (ATM) systems to treat many symptomatic disorders associated with COVID-19. African traditional medicines also use plants for the treatment of viral diseases other than COVID-19, like dengue and chikungunya, as well as non-viral diseases like diabetes and malaria. As such, ATMs need to be examined more closely regarding COVID-19, a view endorsed by WHO (WHO, 2020). A large percentage of COVID19 patients die when comorbidities are present and this is an aspect which should not be overlooked.

Our initial literature search was for plants, which are used in ATM for the treatment of diabetes, malaria, and as many COVID-19 symptoms as possible. The next stage was to examine the reported phytochemicals and pharmacological activities of any selected plants that supported the plant's traditional/ethnic uses. In the final stage, molecular docking studies were conducted on reported phytochemicals of the plant with the main protease Mpro of SARS-CoV-2, which plays a vital role in viral replication and the interface between receptor binding domain (RBD domain) of the Spike protein (S) and its human angiotensin converting enzyme 2 receptor (hACE2), which plays the major role for binding and subsequent cellular entry of the virus. These two proteins of SARS-CoV-2 form major therapeutic targets for their importances in viral replication and viral entry, respectively, and are used in various computational studies for drug discovery against the virus (Wu et al., 2020).

As far back as human history has been recorded, it shows that human beings suffered from diseases and plants have always formed the source of drugs. The practice has continued till now, and about $25 \%$ of the drugs in current use in conventional or allopathic medicine are plant-derived. These drugs include digoxin, artemisinin, vincristine, vinblastine, and atropine, to name only a few (Rates, 2001). Ethnopharmacological approaches to new drug discovery encompasses field observations of traditional medicinal practices, followed by phytochemical and pharmacological research (Süntar, 2020). Because of the huge costs involved in clinical trials and the time required to conduct these trials, prior in silico studies are generally conducted using a variety of programs to learn more about the drug-potential of a phytochemical or its chemical derivatives.

In the present study, we have combined these approaches by first searching out the traditional uses of a plant followed by searches of its phytoconstituents and pharmacological activities. Following preliminary confirmation of the suitability of the plant through literature searchs as per our requirements of being a potential antiCOVID-19 plant (reported ability to alleviate at least a few COVID-19 symptoms as well as one or two comorbidities), the plant Costus afer was selected and a number of the phytochemicals of the plant were subjected to molecular docking analysis with two major proteins of SARS-CoV-2, as described before. Phytochemical screening through molecular docking with main protease Mpro of SARS-CoV-2 for discovery of anti-COVID-19 drugs has been done before in a number of studies (Garg et al., 2020; Joshi et al., 2020; Mahmud et al., 2021); the same applies to molecular docking studies with spike protein receptor binding domain (Basu et al., 2020; Pushkaran et al., 2021).

\section{MATERIALS AND METHODS}

\section{Literature search}

Existing peer-reviewed scientific literature was scanned through various search engines like PubMed, SCOPUS, and Google Scholar to find out review papers and papers dealing with ethnic uses, phytochemicals, and pharmacological activity studies of the plant Costus afer. A number of search terms were used like [Costus afer, review], [Costus afer, ethnobotanical uses, Africa]. For data pertaining to COVID-19, search terms like [COVID-19], and [COVID-19, comorbidities] were used. Boolean operators were used in the search. Selection of articles and their inclusions were prioritized on the basis of their containing search terms in their title, keywords, abstract or full text. We used a narrative mode to present the relevant reports; any meta-analysis was not done because of the scarcity of ethnic, phytochemical and pharmacological reports.

\section{Three-dimensional structure of COVID-19 major protease (3C-like protease or Mpro)}

We used the pdb file (6LU7) of the main protease of SARSCoV-2 (Mpro) in the present study (Liu et al., 2020) following removal of the inhibitor (known as N3) from the pdb file prior to using the protein's structure in our molecular docking studies with the phytochemicals. Monomeric form of the protease was used for molecular docking (Zhavoronkov et al., 2020). Any water or other molecules bound to the monomeric structure was removed prior to molecular docking.

\section{Structure of receptor binding domain (RBD) of spike protein bound} to ACE-2

The structure of novel coronavirus SARS-CoV-2 spike protein receptor-binding domain complexed with its receptor ACE2 was retrieved from the Protein Data Bank (pdb id 6LZG). This structure demonstrates the interaction between Receptor Binding Domain (RBD) of Spike protein and its human receptor, human ACE2 (hACE2). The key residues of RBD that are involved in the interaction are as follows: Lys417, Tyr449, Leu455, Ala475, Glu484, Phe486, Asn487, Tyr489, Gln493, Ser494, Gly496, Gln498, Thr500, and Gly502 (Boison et al., 2019; Muhseen et al., 2020). The authors of the paper targeted the interface between RBD domain of the Spike protein and hACE2. Our intention was to examine for possible disruption in the protein-protein interaction between the Spike protein of SARS-CoV-2 and hACE2 through binding of phytochemicals to this binding region (RBD). Any disruption in this proteinprotein interaction will make it difficult for spike protein to bind to hACE2 and thus cause SARS-CoV-2 to lose its ability to enter the human body. It would be further advantageous if the same phytochemical or phytochemical(s) from a single plant can bind to both Mpro and RBD of S protein. 


\section{Compounds used in docking studies}

A total of 26 phytochemicals present in Costus afer were selected from several papers listing the phytoconstituents of the plant (Ogukwe et al., 2018; Boison et al., 2019). The selection was rather random and did not follow any set rules except for what seemed likely to bind to Mpro of SARS-CoV-2 or the RBD of $S$ protein-hACE2 interface based on the phytochemical structure. Along with the phytochemicals, a control antiviral drug lopinavir was used as standard. Lopinavir is a drug currently under investigation against COVID-19 and has also been tested previously for use against Severe Acute Respiratory Syndrome (SARS) and Middle East Respiratory Syndrome (MERS) viruses (Meini et al., 2020; Yao et al., 2020). Ligand molecules were downloaded from Pubchem (Ihlenfeldt, 2008) in sdf format. They were optimized with the force field type MMFF94 using Openbable softwares and saved as pdbqt format.

\section{Ligand molecular docking studies}

Molecular docking (blind) was conducted using AutoDock Vina (Trott \& Oslon, 2010). In blind docking there is no assumption on the binding site (Meng et al., 2011). We report $\Delta G$ values as an average of the top values from the docking program. In our figures, we show the pose of some phytochemicals bound to SARS-CoV-2 main protease as well as RBD of S protein-hACE2 interface, as obtained from PyMOL and displayed in Discovery Studio (Studio, 2015) as shown before in our previous studies (Hasan et al., 2020; Bondhon et al., 2021). It is to be noted that the lower the predicted binding energies $(\Delta G)$ of a phytochemical to Mpro or RBD of $S$ protein, the higher will be the binding affinity of the phytochemical to the protein.

\section{Lipinski's rule of five}

Lipinski's rule of 5 or Ro5 (Giménez et al., 2010; Fernandes et al., 2016) was followed to determine the drug like properties of the phytochemicals of Costus afer in the present work. The rule states that molecules, which are poorly absorbed by intestinal wall (that is oral bioavailability is not good) would present any two or more of these characteristics: molecular weight more than 500, lipophilicity $(\log P>5)$, hydrogen-bond (HB) donor groups (expressed as the sum of $\mathrm{OHs}$ and $\mathrm{NHs}$ groups) more than 5, more than $10 \mathrm{HB}$ acceptor groups (expressed as the sum of Os and Ns atoms), and molar refractivity outside a range of 40-130. Lipinski's rule has its violations and it may be mentioned that a number of drugs (like artovastatin and montelucast) have more than two violations of the rule (Giménez et al., 2010). From 2000 to 2014 , out of the 38 central nervous system drugs introduced, $32 \%$ violated one or more aspects of Lipinski's rule (Bondhon et al., 2021). Lipinski's Ro5 still is advantageous for giving general ideas on the drug suitability of a given compound.

\section{Biological activity prediction (ADME analysis)}

The phytochemicals were evaluated for potential bioactivity (ADME or absorption, distribution, metabolism and excretion). The various parameters were evaluated with the aid of the software Molinspiration (www.molinspiration.com, Nova Ulica, Slovensky Grob, Slovak Republic) (Rakib et al., 2020).

\section{Results and Discussion}

Costus afer Ker-Gawl (Costaceae/Zingiberaceae) is commonly known in English as ginger lily and spiral ginger. It is an evergreen perennial. Its habitat ranges from Senegal and Ethiopia to Angola, Malawi, and Tanzania in sub-Saharan
Africa. It can grow up to 4 meters high [https://pfaf.org/user/ Plant.aspx? Latin Name $=$ Costus + afer $]$.

\section{Ethnic uses}

A paper by Boison and colleagues published in 2019 (Boison et al., 2019) summarizes the various ethnic uses of this plant. These include "inflammation, arthritis, stomach-ache, cough, sore throat, measles, malaria, chicken pox, influenza, genital herpes, purgative, laxative, diabetes mellitus, wound healing, diuretic, aperient, jaundice, fever, leprosy, gastric ulcer, colic, hypertension, hemorrhoids, toothache, Central Nervous System (CNS) depression, helminthic disorder, hepatic disorder, miscarriage, gonorrhea, impotency, ear infection, conjunctivitis, and oligospermia". The common symptoms of non-complicated COVID-19 as mentioned before (Sheikhi et al., 2020) are marked in bold in the ethnic uses of C. afer in Africa as summarized by Boison et al. (2019) and given above, along with bold markings of disorders during moderate to severe COVID-19 infections. Also, to be mentioned is that inflammation, influenza, stomach ache, and other types of pain can also develop in COVID-19 patients like myalgia, arthralgia, headache, and chest pain (Weng et al., 2021). Among them, the most important comorbidities are possibly diabetes, malaria, and hypertension. CNS involvement and neurological manifestations are also increasingly described in COVID-19 patients (AsadiPooya and Simani, 2020), as well as jaundice (Fierro, 2020).

\section{Pharmacological activity validations of ethnic uses}

Pharmacological activity studies with Costus afer crude extracts or phytochemicals, which are relevant to COVID-19 symptoms and comorbidities are summarized in Table 1 . It is to be noted that this is not an exhaustive review, rather some articles were chosen, which the authors (in their opinion) thought best described the subject. One thing is clear from ethnic literature and pharmacological activity studies (cited and not cited) that two of the disorders most studied and validated by researchers are the use of the plant against diabetes and malaria.

\section{Molecular docking studies}

Altogether 26 phytochemicals of Costus afer were evaluated for their binding affinities to Mpro and RBD of S protein of SARS-CoV-2. The results are shown in Table 2 and the phytochemical structures are shown in Figure 1. Among the 26 phytochemicals, the steroidal saponin aferoside $C$ showed the least predicted binding energy (that is stronger binding affinity) for both Mpro and $\mathrm{S}$ proteins, with $\Delta \mathrm{G}$ values at -8.8 and $-10.4 \mathrm{kcal} / \mathrm{mol}$, respectively. Besides aferoside $\mathrm{C}$, none of the other phytochemicals showed any significant predicted binding energies with Mpro. However, suginal, dibutyl phthalate, nerolidol, and alpha-terpinene showed high binding affinities for RBD of $S$ protein, with predicted $\Delta G$ values of $-8.2,-7.2,-7.2$, and $-7.1 \mathrm{kcal} / \mathrm{mol}$, respectively. The results indicate that at least five phytochemicals of $C$. afer may have the potential to block viral entry into human cells.

Like Mpro of SARS, Mpro of SARS-CoV-2 is catalytically active as a dimer. Each monomeric unit contains three domains, namely, domain I consisting of amino acid residues 8-101, domain II (amino acid residues 102-184), and domain III (amino acid residues 201-306) (Zhang et al., 2020). Although domain III does not directly participate in interacting with the substrate, removal of domain III results in an inactive protease for domain III is involved in regulating dimerization of Mpro (Amin et al., 2021) and dimerization is necessary for the protease to be catalytically active (Gimeno et al., 2020). 
Table 1. Reported pharmacological studies with Costus afer relevant to COVID-19 symptoms and comorbidities

\begin{tabular}{lll}
\hline $\begin{array}{l}\text { COVID-19 symptom } \\
\text { or comorbidity }\end{array}$ & Pharmacological activity studies & References \\
\hline
\end{tabular}

Analgesic and anti- Using rat models, it was shown that leaf ethanol extract and stem juice (ljioma et al., 2014)

inflammatory effect demonstrated antinociceptive activities.

Hexane fraction of $70 \%$ methanolic leaf extract showed anti-inflammatory
properties in vitro screening assays like anti-denaturation of protein, erythrocyte stabilization assay, and anti-proteinase activity.

Anti-inflammatory effect observed in carrageenan, arachidonic acid, formaldehyde, and Complete Freund's Adjuvant-induced arthritis in male albino rats with hexane

(Anyasor et al., 2014) fraction of leaves.

\begin{tabular}{ll}
\hline Hepatoprotective & Aqueous extract of stems significantly reduced total bilirubin concentrations in \\
serum of high fat diet-induced hyperlipidemic rats.
\end{tabular}

(Chioma et al., 2020) serum of high fat diet-induced hyperlipidemic rats.

Hepatoprotective activity seen in rats with aqueous leaf extract against cyclosporine A induced hepatotoxicity.

Oral administration of aqueous fraction of methanolic extract of leaves protected rats against diethylnitrosoamine-induced hepatocellular carcinoma.

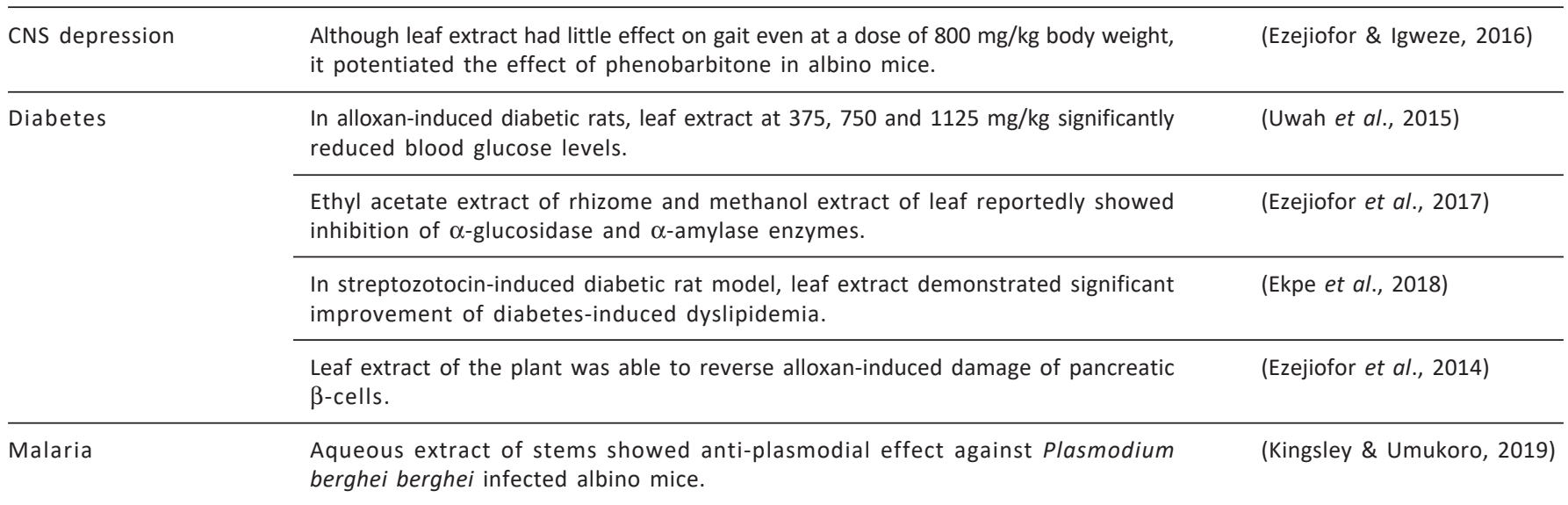

Ethanol extract of aerial parts of the plant reportedly demonstrated strong anti-
plasmodial activity in vitro against field isolates and chloroquine sensitive 3D7
strains of Plasmodium falciparum using Plasmodium lactate dehydrogenase (pLDH)
assay. No toxicity of the extract was observed.
Methanol stem extract of the plant and residual aqueous fraction showed
significant and dose-dependent inhibitions of schizont growth in chloroquine-
sensitive, chloroquine-resistant, and artemether-resistant Plasmodium falciparum
strains with $\mathrm{IC}_{50}$ values of 8.86 and $10.51,11.27$ and 15.05 , and 10.30 and $11.23 \mu \mathrm{g} /$
mL against chloroquine-sensitive, chloroquine-resistant and artemether-resistant
strains, respectively.

(Tiko et al., 2020)

(Ezejiofor \& Orisakwe, 2015)

(Anyasor et al., 2014, 2020)

Although leaf extract had little effect on gait even at a dose of $800 \mathrm{mg} / \mathrm{kg}$ body weight,

In alloxan-induced diabetic rats, leaf extract at 375, 750 and $1125 \mathrm{mg} / \mathrm{kg}$ significantly

blood glucose levels.

hibition of $\alpha$-glucosidase and $\alpha$-amylase enzymes. 


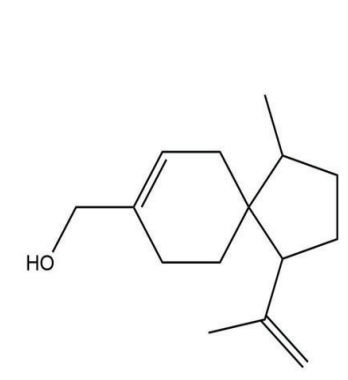

Acoradienol

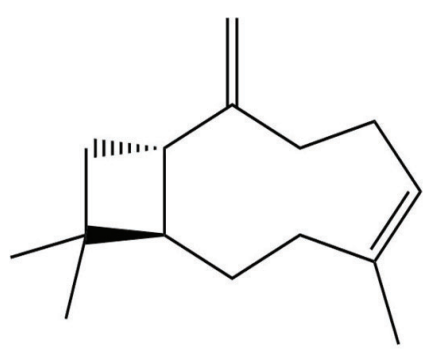

Caryophyllene

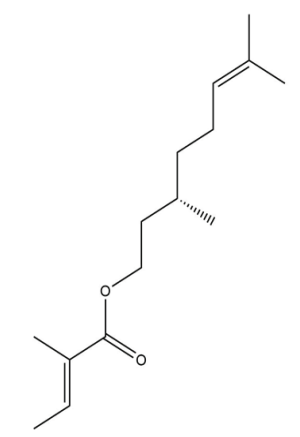

Citronellyl tiglate<smiles>CC(C)=CCC/C(C)=C\CC/C(C)=C\CO</smiles>

Z,Z-Farnesol<smiles>CCCCc1ccc(C(=O)O)c(C(=O)O)c1CCCC</smiles>

Dibutyl_phthalate

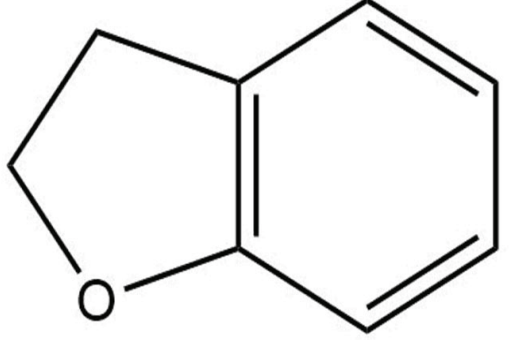

Coumaran<smiles>CC(C)=CCCC(C)=CCCC(C)CO</smiles>

Z-Dehydro-apo-farnesol

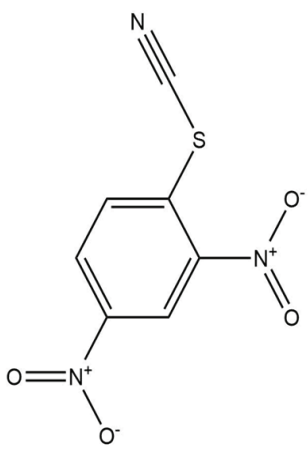

2,4-Dinitrophenyl thiocyanate

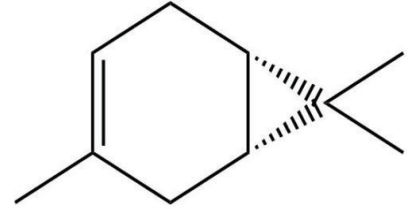

3-Carene

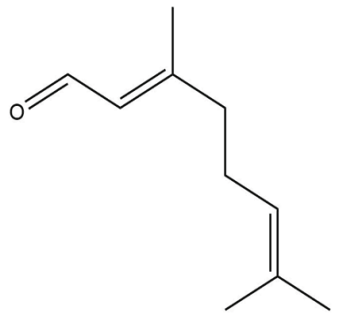

Citral

Caryophylene oxide

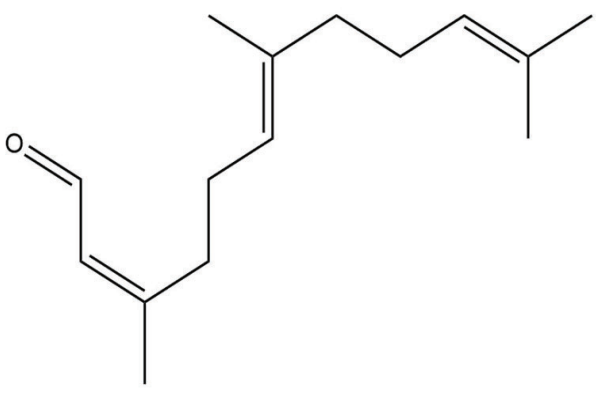

Z-Dihydro-farnesal<smiles>CC(C)=CCC/C(C)=C/CC/C(C)=C\CO</smiles>

Z-Dihydro-farnesol<smiles>C=C(C)C1CCC2(C)CCCC(=C)C2C1</smiles>

Helmiscapene

Figure 1. Structures of Costus afer phytochemicals used in molecular docking studies. 


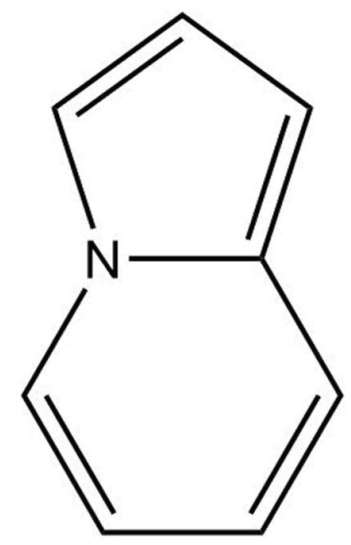

Indolizin<smiles>C/C(=C\CO)CCC[C@H](C)CCC[C@H](C)CCCC(C)C</smiles>

Phytol

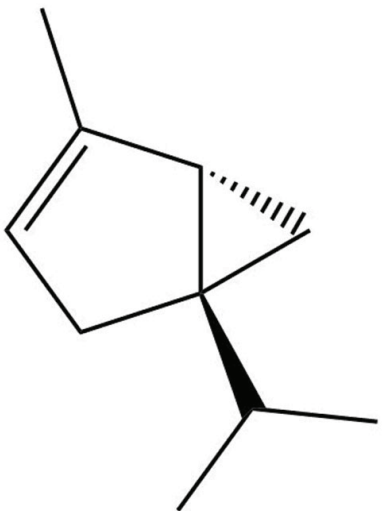

Theaspirane

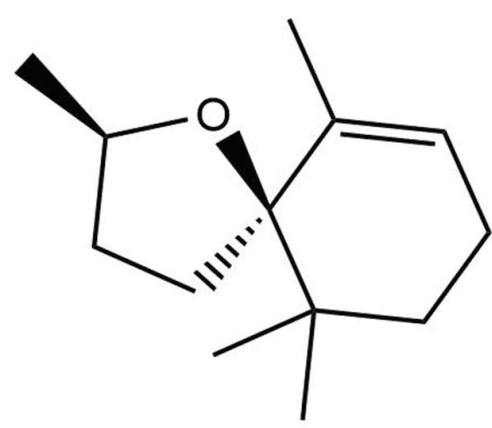

Thujene
cis-Piperitol

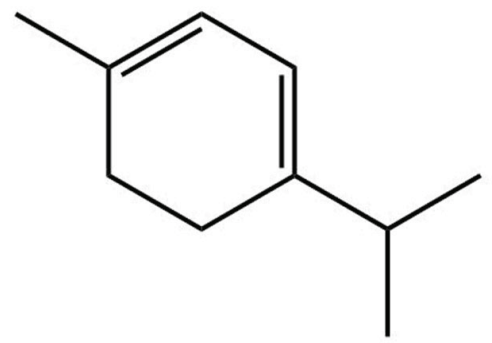

Terpinene

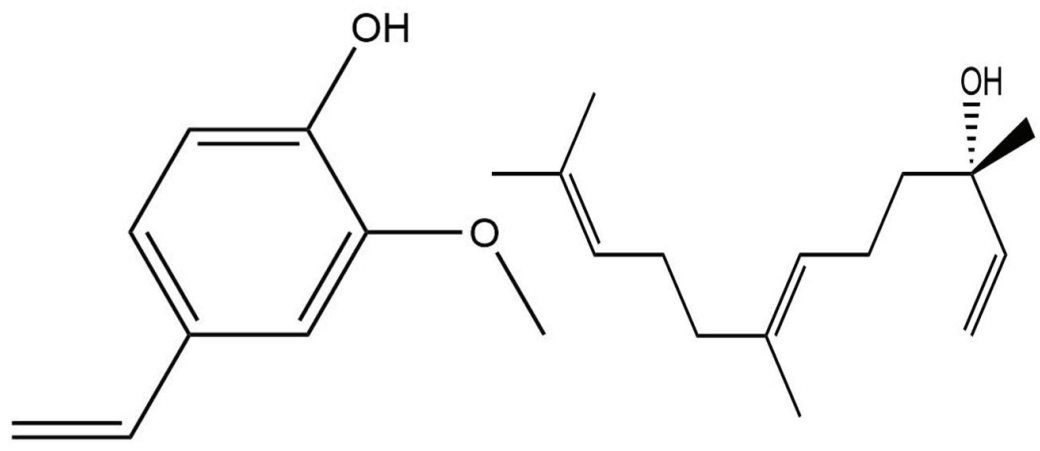

Nerolidol

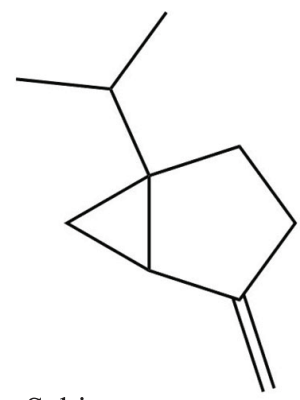

Sabinene

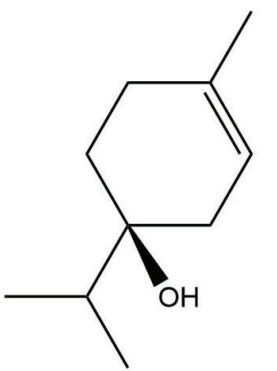

Terpinen-4-ol

Figure 1. (continued). 

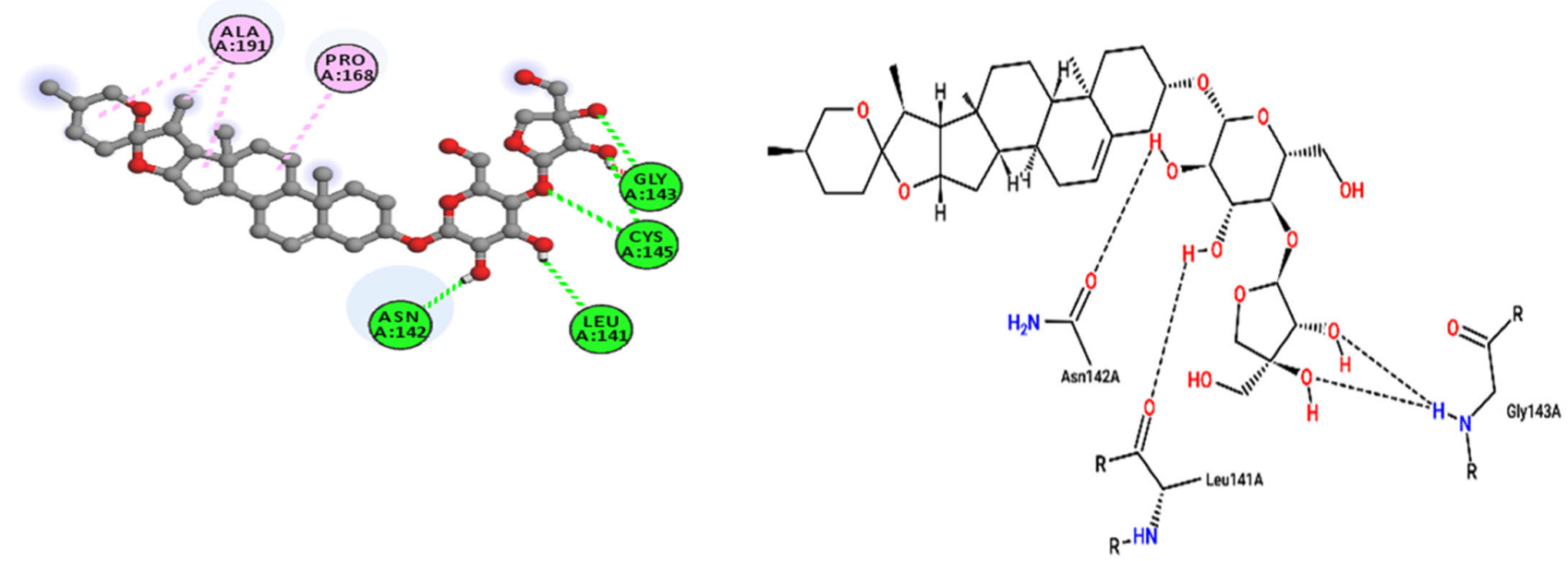

Interactions

Conventional Hydrogen Bond $\square$ Alkyl

Unfavorable Donor-Donor

Figure 2. Depictions of aferoside $C$ interactions with Mpro of SARS-CoV-2.

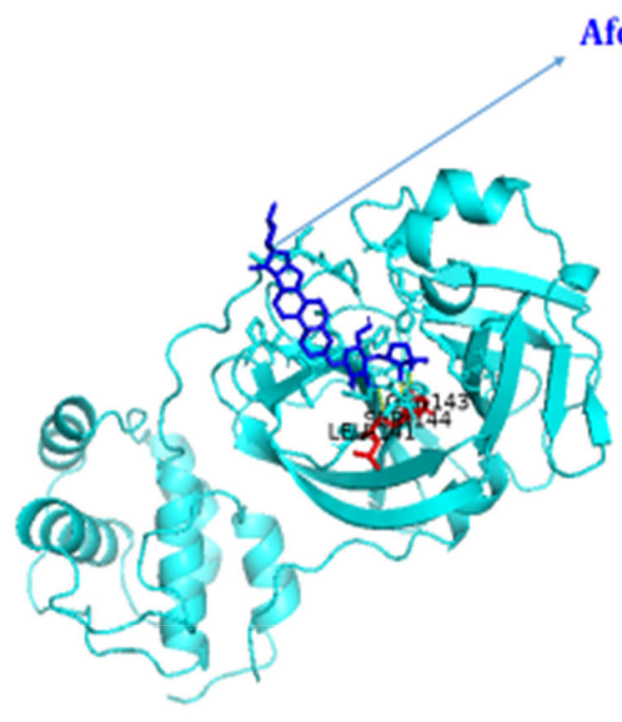

Aferoside C

Red colored amino acid residues are involved in polar interactions with aferoside $\mathrm{C}$

Figure 3. Pymol diagram depicting polar interactions between aferoside $\mathrm{C}$ and Mpro.

low binding energies (that is high binding affinities) with $\mathrm{S}$ protein RBD-hACE2 interface (especially suginal), also makes them attractive candidates as therapeutics against SARSCoV-2 for potential ability to block viral entry into human host cells.

Physico-chemical properties of selected phytochemicals and ADME analysis

Physicochemical properties of selected phytochemicals demonstrating high binding affinities for Mpro and/or $S$ protein RBD-hACE2 interface including violations of Lipinski's Ro5 were analyzed as mentioned before (Daina et al., 2017; Rakib et al., 2020). Interestingly, dibutyl phthalate, suginal, and nerolidol had zero violations of Lipinski's Ro5; aferoside violated all 5 rules. The results are shown in Table 3. However, it has to be pointed out that Lipinski's rule of five, although applicable to "orally bioavailable small-molecule drug design", is not applicable for "natural product and semisynthetic natural product drugs" (Zhang and Wilkinson, 2008). New molecular entities (NMEs), especially biological, are 

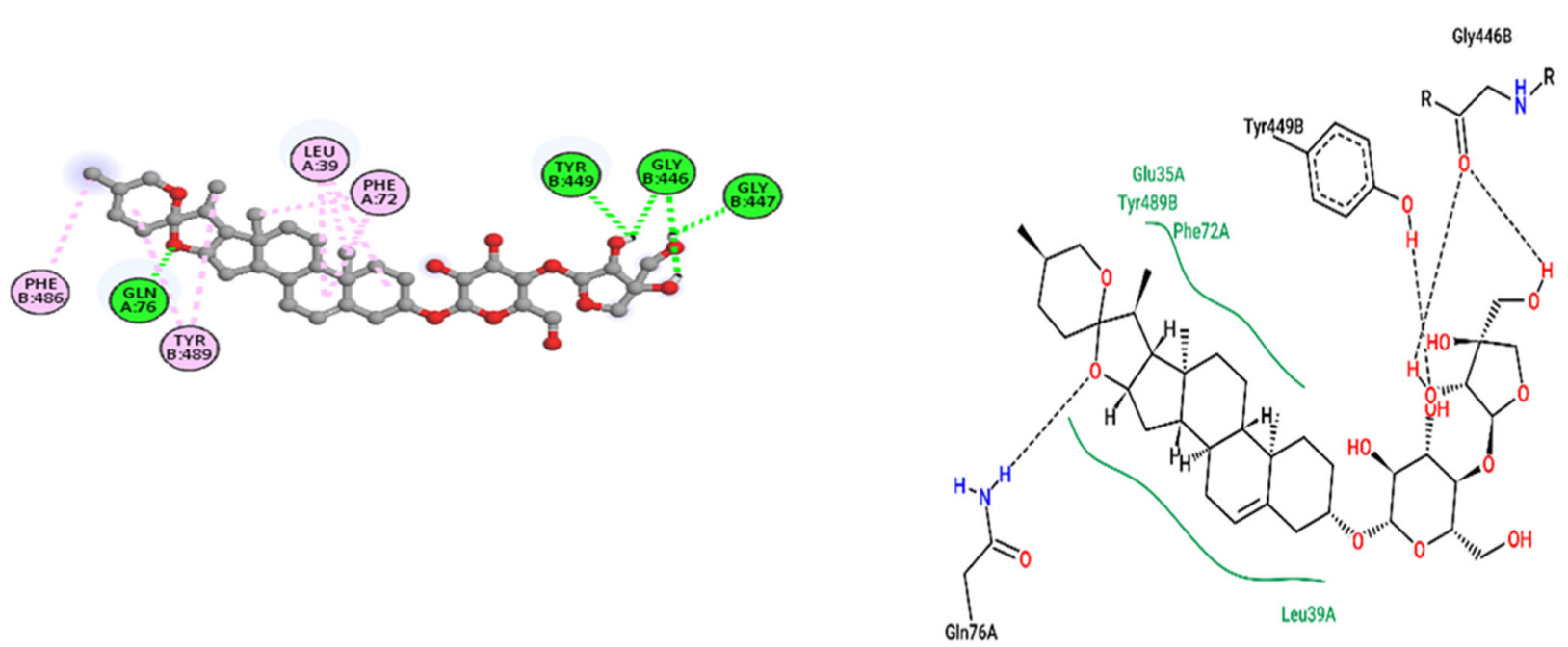

Interactions

Conventional Hydrogen Bond

Alkyl

Figure 4. Depictions of aferoside C interactions with RBD of S protein of SARS-CoV-2.

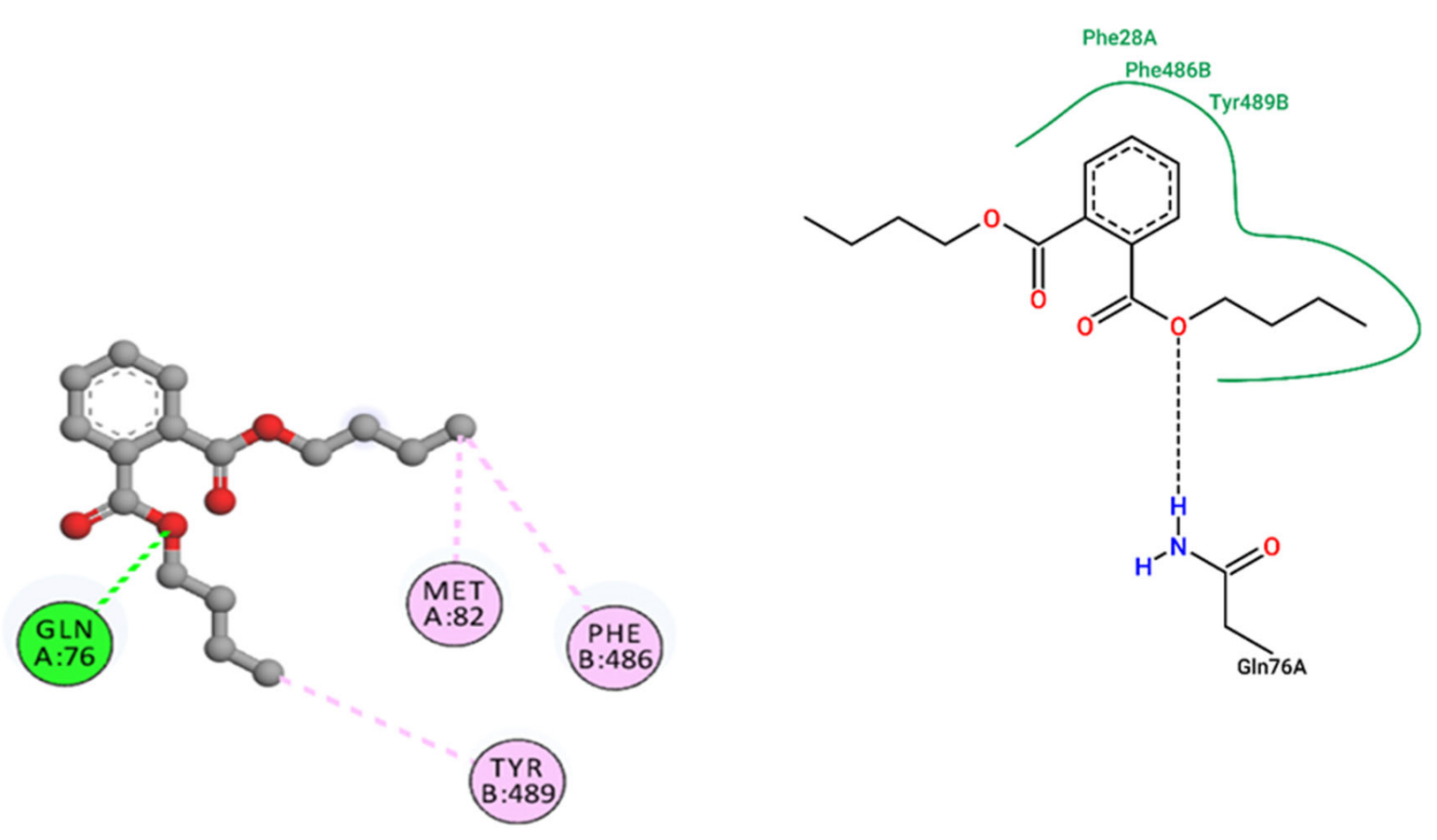

Interactions

Conventional Hydrogen Bond

Alky

Figure 5. Depictions of dibuytl phthalate interactions with RBD of S protein of SARS-CoV-2. 
Table 2. Binding energies of Costus afer phytochemicals to Mpro (without bound N3) and spike protein RBD-ACE2 interface

\begin{tabular}{|c|c|c|}
\hline \multirow[b]{2}{*}{ Phytochemicals } & \multicolumn{2}{|c|}{ Binding energy $(\Delta \mathrm{G}=\mathrm{akcal} / \mathrm{mol})$} \\
\hline & $\begin{array}{c}\text { Mpro } \\
\text { (without N3) }\end{array}$ & $\begin{array}{c}\text { Spike } \\
\text { protein (S) }\end{array}$ \\
\hline Beta-Acoradienol & -4.5 & -6.5 \\
\hline Aferoside C & -8.8 & -10.4 \\
\hline 3-Carene & -4.9 & -5.3 \\
\hline Caryophyllene & -6.0 & -6.2 \\
\hline Caryophyllene oxide & -6.3 & -6.5 \\
\hline Citral & -4.2 & -6.3 \\
\hline Citronellyl tiglate & -4.2 & -6.5 \\
\hline Coumaran & -4.7 & -6.2 \\
\hline Z-Dihydro-farnesal & -4.4 & -5.5 \\
\hline Z,Z-Farnesol & -5.0 & -6.7 \\
\hline Z-Dehydro-apo-farnesol & -4.6 & -6.8 \\
\hline Z-Dihydro-farnesol & -4.6 & -5.5 \\
\hline Dibutyl phthalate & -4.9 & -7.2 \\
\hline 2,4-Dinitrophenyl thiocyanate & -5.0 & -5.6 \\
\hline Beta-Helmiscapene & -5.8 & -6.6 \\
\hline Indolizin & -4.6 & -5.8 \\
\hline 2-Methoxy-4-vinylphenol & -5.3 & -6.5 \\
\hline Nerolidol & -5.4 & -7.2 \\
\hline Phytol & -4.5 & -5.0 \\
\hline cis-Piperitol & -4.8 & -6.4 \\
\hline Sabinene & -4.5 & -6.3 \\
\hline Suginal & -6.5 & -8.2 \\
\hline Alpha-Terpinene & -5.1 & -7.1 \\
\hline Terpinen-4-ol & -5.1 & -6.5 \\
\hline Theaspirane & -5.8 & -5.9 \\
\hline Alpha-Thujene & -4.8 & -6.7 \\
\hline
\end{tabular}

increasingly being approved by the US Food and Drug Administration as parenteral drugs [https://dcatvci.org/4793parenteral-drugs-tracking-new-drug-approvals] and that can possibly apply to biological compounds like aferoside C.

Taking all the results into account, five phytochemicals of $C$. afer stand out (among the phytochemicals tested) for their strong binding affinities to Mpro or S protein RBD-hACE2 interface or both suggesting that they have the potential to be COVID-19 therapeutics. These phytochemicals are aferoside $C$, suginal, dibutyl phthalate, nerolidol, and alphaterpinene. Phthalic acid esters may have antiviral activity as demonstrated for 2"-(methoxycarbonyl)-5"- methylpentyl 2'-methylhexyl phthalate from the aerial parts of the Bangladeshi mangrove fern Acrostichum aureum, which was found to show antiviral activity against dengue, chikungunya, and human parainfluenza virus (Uddin et al., 2013). Any antiviral activities of the other four compounds have not been reported to our knowledge. The limitation of this study is that it relies on only in silico studies to determine antiSARS-CoV-2 potential of various phytochemicals present in Costus afer. It was also not possible in this study to evaluate all phytochemicals of the plant for their anti-SARS-CoV-2 potential. The strong points in the study are (I) to highlight the fact that COVID-19 comorbidities should be taken into account during its treatment to decrease the mortality rate and notes the weakness of conventional treatment in trying to deal with both COVID-19 and comorbidities, given the fact that till now there is not a single drug against COVID-19 with or without comorbidities; (II) this study points to an alternative method of treatment of COVID-19 and a number of major comorbidities like malaria and diabetes with the use of a single plant (crude extract primarily), which even though some researchers might find it traditional, but traditional approaches have been endorsed by WHO to treat COVID-19 following appropriate clinical trials and toxicity determinations; and (III) last but not the least, the present study points to a pragmatic way of using a three pronged approach of ethnic use reports, pharmacological activity reports, and in silico studies with reported phytochemicals of a given plant to come to a rational conclusion of the suitability of a plant's crude extract(s) and or phytochemicals to treat COVID-19. The value of this approach is that instead of costly imported synthetic drugs, this approach can be used to identify readily affordable and available medicinal plants in one's own country, region or vicinity for further quick analysis, which may turn out to be the key in saving lives during pandemics caused by new and emerging infectious agents. A further point is that many conventional (allopathic) drugs are phytochemicals (like artemisinin), and this approach presents a quick route of discovery of allopathic drugs.

\section{CONCLUSION}

From a combination of previously published ethnic uses and pharmacological activity studies on Costus afer, a number of phytochemicals reported from the plant were evaluated in molecular docking studies for their predicted binding energies to SARS-CoV-2 Mpro, and the spike protein (S) receptor binding domain (RBD) interface with the virus' human receptor ACE2 (hACE2). Our results indicate that if both ethnic uses of the plant and currently done in silico studies are validated through actual laboratory studies and clinical trials, the plant and its phytochemical(s) may prove to be an asset in the simultaneous treatment of COVID-19 and major comorbidities like malaria and diabetes. As such, the plant holds immense potential for particularly Sub Saharan and South Asian countries, which are fast becoming new epicenters for COVID-19 and in which countries, malaria and diabetes are still rampant.

Table 3. Physico-chemical properties of selected compounds of Costus afer

\begin{tabular}{|c|c|c|c|c|c|c|}
\hline Compound Name & $\begin{array}{l}\text { Molecular } \\
\text { weight }\end{array}$ & $\begin{array}{c}\text { Number of } \mathrm{H} \text {-Bond } \\
\text { Acceptors }\end{array}$ & $\begin{array}{c}\text { Number of } \\
\text { H-Bond Donors }\end{array}$ & $\log P$ & $\begin{array}{c}\text { Molar } \\
\text { Refractivity }\end{array}$ & $\begin{array}{l}\text { Number of } \\
\text { Violation }\end{array}$ \\
\hline Aferoside C & 708.88 & 12 & 6 & 5.25 & 180.43 & 5 \\
\hline Caryophylene oxide & 220.35 & 1 & 0 & 3.15 & 68.27 & 0 \\
\hline Caryophyllene & 204.35 & 0 & 0 & 3.29 & 68.78 & 0 \\
\hline Suginal & 314.42 & 3 & 1 & 2.72 & 92.26 & 0 \\
\hline Dibutyl phthalate & 278.34 & 4 & 0 & 2.97 & 77.84 & 0 \\
\hline Nerolidol & 222.37 & 1 & 1 & 3.64 & 74.00 & 0 \\
\hline
\end{tabular}




\section{ACKNOWLEDGEMENTS}

The study was funded solely by the authors. M.L.P. is grateful to Project CICECO-Aveiro Institute of Materials, UIDB/50011/ 2020 and UIDP/50011/2020, national funds by FCT/MCTES.

\section{Conflicts of interest}

All authors declare that they have no conflicts of interest.

\section{REFERENCES}

Amin, S.A., Banerjee, S., Singh, S., Qureshi, I.A., Gayen, S. \& Jha, T. (2021). First structure-activity relationship analysis of SARS-CoV-2 virus main protease (Mpro) inhibitors: an endeavor on COVID-19 drug discovery. Molecular Diversity 25: 1827-1838. https://doi.org/10.1007/s11030-020-10166-3

Anyasor, G.N., Funmilayo, O., Odutola, O., Olugbenga, A. \& Oboutor, E.M. (2015). Evaluation of Costus afer Ker-Gawl. in vitro anti-inflammatory activity and its chemical constituents identified using gas chromatography-mass spectrometry analysis. Journal of Coastal Life Medicine 3: 132-138. https://doi.org/10.12980/JCLM.3.2015APJTB-20140186

Anyasor, G.N., Idowu, D.P. \& Nabofa, W. (2020). Evaluation of the hepatoprotective effect of oral administration of aqueous fraction of methanolic extract of Costus afer leaves during induction of hepatocellular carcinoma with diethylnitrosoamine in rats. Comparative Clinical Pathology 29: 733-744. https://doi.org/10.1007/s00580-020-03124-w

Anyasor, G.N., Onajobi, F., Osilesi, O., Adebawo, O. \& Oboutor, E.M. (2014). Anti-inflammatory and antioxidant activities of Costus afer Ker Gawl. hexane leaf fraction in arthritic rat models. Journal of Ethnopharmacology 155: 543-551. https://doi.org/10.1016/j.jep.2014.05.057

Asadi-Pooya, A. \& Simani, L. (2020). Central nervous system manifestations of COVID-19: A systematic review. Journal of the Neurological Sciences 413: 116832. https://doi.org/ 10.1016/j.jns.2020.116832

Basu, A., Sarkar, A. \& Maulik, U. (2020). Molecular docking study of potential phytochemicals and their effects on the complex of SARS-CoV2 spike protein and human ACE2. Scientific Reports 10: 17699. https://doi.org/10.1038/s41598020-74715-4

Boison, D., Adinortey, C.A., Babanyinah, G.K., Quasie, O., Agbeko, R., Wiabo-Asabil, G.K. \& Adinortey, M.B. (2019). Costus afer: A systematic review of evidence-based data in support of its medicinal relevance. Scientifica 2019: 3732687. https://doi.org/10.1155/2019/3732687

Bondhon, T.A., Fatima, A., Jannat, K., Hasan, A., Jahan, R., Nissapatorn, V., Wiart, C., de Lourdes, P.M. \& Rahmatullah, M. (2021). In silico screening of Allium cepa phytochemicals for their binding abilities to SARS and SARS-CoV-2 C3-like protease and COVID-19 human receptor ACE-2. Tropical Biomedicine 38: 214-221. https://doi.org/10.47665/tb.38.2.060

Chioma, A.C., Albert, A.C. \& Ijeoma, O.R. (2020). Effect of aqueous extract of Costus afer stems on the serum proteins and bilirubin levels of high fat diet induced hyperlipidemic rats. Asian Journal of Biochemistry, Genetics and Molecular Biology 6: 57-64. https://doi.org/10.9734/ ajbgmb/2020/v6i230150

Couvreur, T.L.P. (2015). Odd man out: why are there fewer plant species in African rain forests? Plant Systematics and Evolution 301: 1299-1313. https://doi.org/10.1007/s00606014-1180-z
Daina, A., Michielin, O. \& Zoete, V. (2017). SwissADME: a free web tool to evaluate pharmacokinetics, drug-likeness and medicinal chemistry friendliness of small molecules. Scientific Reports 7: 42717. https://doi.org/10.1038/srep42717

Ekpe, I.P., Udosen, E.O., Amaechi, D. \& Yisa, B.N. (2018). Impact of ethanolic extract of Tecoma stans and Costus afer leaves on lipid profile status of streptozotocin induced diabetic Wistar rats. International Journal of Sciences 4: 16-20.

Ezejiofor, A.N. \& Orisakwe, O.E. (2015). Assessment of the hepatoprotective and antioxidant effect of aqueous leaf extract of Costus afer "Ker Gawl" on cyclosporine A induced hepatotoxicity. Toxicology International 22: 83. https:// doi.org/10.22506/ti/2015/v22/i3/137629

Ezejiofor, A.N. \& Igweze, Z. (2016). Some biological and CNS properties of the ethanolic extract of Costus afer stem Ker Gawl (Costaceae). World Journal of Pharmacy and Pharmaceutical Sciences 5: 337-352.

Ezejiofor, A.N., Igweze, Z.N., Udowelle, N.A. \& Orisakwe, O.E. (2017). Histopathological and biochemical assessments of Costus afer stem on alloxan-induced diabetic rats. Journal of Basic and Clinical Physiology and Pharmacology 28: 383-391. https://doi.org/10.1515/jbcpp-2016-0039

Ezejiofor, A.N., Orish, C.N. \& Orisakwe, O.E. (2014). Cytological biochemical studies during the progression of alloxaninduced diabetes and possible protection of an aqueous leaf extract of Costus afer. Chinese Journal of Natural Medicines 12: 745-752. https://doi.org/10.1016/S18755364(14)60114-X

Fernandes, T.B., Segretti, M.C.F., Polli, M.C. \& Parise-Filho, R. (2016). Analysis of the applicability and use of Lipinski's rule for central nervous system drugs. Letters in Drug Design \& Discovery 13: 999-1006. https://doi.org/10.2174/ 1570180813666160622092839

Fierro, N.A. (2020). COVID-19 and the liver: What do we know after six months of the pandemic? Annals of Hepatology 19: 595-596. https://doi.org/10.1016/j.aohep.2020.09.001

Garg, S., Anand, A., Lamba, Y. \& Roy, A. (2020). Molecular docking analysis of selected phytochemicals against SARS-CoV-2 $\mathrm{M}^{\text {pro }}$ receptor. Vegetos 33: 766-781. https://doi.org/10.1007/ s42535-020-00162-1

Giménez, B.G., Santos, M.S., Ferrarini, M. \& Fernandes, J.P.S. (2010). Evaluation of blockbuster drugs under the Ruleof-five. Pharmazie 65: 148-152. https://doi.org/10.1691/ ph. 2010.9733

Gimeno, A., Mestres-Truyol, J., Ojeda-Montes, M.J., Macip, G., Saldi-var-Espinoza, B., Cereto-Massagué, A., Pujadas, G. \& Garcia-Vallvé, S. (2020). Prediction of novel inhibitors of the main protease (M-pro) of SARS-CoV-2 through consensus docking and drug reposition. International Journal of Molecular Sciences 21: 3793. https://doi.org/ 10.3390/ijms21113793

Hasan, A., Jahan, R., Jannat, K., Bondhon, T.A., Hossan, M.S., Mazumder, S., Fatima, A., de Lourdes, P.M., Wiart, C., Nissapatorn, V. et al. (2020). Evaluation of Lens culinaris phytochemicals in binding to the 3C-like protease of SARSCoV-2 - A molecular docking approach. Indian Journal of Medical Sciences 72: 172-176. https://doi.org/10.25259/ IJMS_219_2020

Ihlenfeldt, W.D. (2008). PubChem. In: Applied Chemoinformatics, pp. 245-258. https://doi.org/10.1002/9783527806539.ch6e

Ijioma, S.N., Nwosu, C.O., Emelike, C.U., Okafor, A.I. \& Nwankwo, A.A. (2014). Antinociceptive property of Costus afer Ker stem juice and ethanol leaf extract in albino rats. Journal of Medical Sciences 2: 14-19. 
International Diabetes Federation (2017). Regional fact sheet: Africa, World Diabetes Foundation. https://www. worlddiabetesfoundation.org/files/regional-fact-sheetafrica. Accessed 11 November 2021

Jimoh, A.F.A., Maiha, B.B., Chindo, B.A., Ejiofor, J.I., Ehinmidu, J.O., Atang, D.A. \& Azi, J.Y. (2019). In vitro antiplasmodial activity of methanol stem extract of Costus afer Ker Gawl. (Costaceae) and its residual aqueous fraction against some drug-sensitive and drug-resistant Plasmodium falciparum strains. Tropical Journal of Natural Product Research 3: 162-169. https://doi.org/10.26538/tjnpr/v3i5.3

Joshi, T., Joshi, T., Sharma, P., Mathpal, S., Pundir, H., Bhatt, V. \& Chandra, S. (2020). In silico screening of natural compounds against COVID-19 by targeting Mpro and ACE2 using molecular docking. European Review for Medical and Pharmacological Sciences 24: 4529-4536. https://doi. org/10.26355/eurrev_202004_21036

Kingsley, E. \& Umukoro, B.O. (2019). The effect of the aqueous extract of bush cane (Costus afer) stem on Plasmodium berghei infected albino mice. International Journal of Latest Technology in Engineering, Management and Applied Science (ILTEMAS) 9: 92-97.

Liu, X., Zhang, B., Jin, Z., Yang, H. \& Rao, Z. (2020). The crystal structure of COVID-19 main protease in complex with an inhibitor N3. RCSB Protein Data Bank 10. https://doi.org/ 10.2210/PDB6LU7/PDB

Mahmud, S., Biswas, S., Paul, G.K., Mita, M.A., Promi, M.M., Afrose, S., Hasan, M.R., Zaman, S., Uddin, M.S., Dhama, K. et al. (2021). Plant-based phytochemical screening by targeting main protease of SARS-CoV-2 to design effective potent inhibitors. Biology 10: 589. https://doi.org/10.3390/ biology10070589.

Meini, S., Pagotto, A., Longo, B., Vendramin, I., Pecori, D. \& Tascini, S. (2020). Role of lopinavir/ritonavir in the treatment of COVID-19: A review of current evidence, guideline recommendations, and perspectives. Journal of Clinical Medicine 9: 2050. https://doi.org/10.3390/ jcm9072050.

Meng, X.Y., Zhang, H.X., Mezei, M. \& Cui, M. (2011). Molecular docking: A powerful approach for structure-based drug discovery. Current Computer Aided Drug Discovery 7: 146-157. https://doi.org/10.2174/157340911795677602

Muhseen, Z.T., Hameed, A.R., Al-Hasani, H.M.H., Tahir ul Qamar, M. \& Li, G. (2020). Promising terpenes as SARSCoV-2 spike receptor-binding domain (RBD) attachment inhibitors to the human ACE2 receptor: Integrated computational approach. Journal of Molecular Lipids 320: 114493. https://doi.org/10.1016/j.molliq.2020.114493

Nuwagira, E. \& Muzoora, C. (2020). Is sub-Saharan Africa prepared for COVID-19? Tropical Medicine and Health 48: 18. https://doi.org/10.1186/s41182-020-00206-x

Ogukwe, C.E., Akalezi, C.O., Anukam, B.N., Idika, I.D. \& Awosu, E.A. (2018). Gas chromatography-mass spectrophotometric (GC-MS) studies on therapeutic potentials of Costus afer Ker Gawl leaves. World Journal of Pharmaceutical Research 7: 78-88. https://doi.org/10.20959/wjpr20189-11232

Orish, V.N. (2015). Economic burden of infectious diseases and benefit of control and prevention in sub-Saharan Africa. Open Access Library Journal 2: 1-6. https://doi.org/ 10.4236/oalib.1102138.

Pushkaran, A.C., Nath, E.N.P., Melge, A.R., Puthiyedath, R. \& Mohan, C.G. (2021). A phytochemical-based medication search for the SARS-CoV-2 infection by molecular docking models towards spike glycoproteins and main proteases. RSC Advances 11: 12003-12014. https://doi.org/10.1039/ DORA10458B
Rakib, A., Paul, A., Chy, M.N.U., Sami, S.A., Baralm S.K., Majumder, M., Tareq, A.M., Amin, M.N., Shahriar, A., Uddin, M.Z. et al. (2020). Biochemical and computational approach of selected phytocompounds from Tinospora crispa in the management of COVID-19. Molecules 25: 3936. https://doi.org/10.3390/molecules25173936.

Rates, S.M.K. (2001). Plants as source of drugs. Toxicon 39: 603613. https://doi.org/10.1016/S0041-0101(00)00154-9

Sheikhi, K., Shirzadfar, H. \& Sheikhi, M. (2020). A review on novel coronavirus (Covid-19): Symptoms, transmission and diagnosis tests. Research in Infectious Diseases and Tropical Medicine 2(1): 1-8. DOI: 10.33702/ridtm.2020.2.1.1

Studio, D. (2015). Dassault Systemes BIOVIA, Discovery studio modelling environment, Release 4.5. Accelrys Software Inc: 98-104.

Süntar, I. (2020). Importance of ethnopharmacological studies in drug discovery: role of medicinal plants. Phytochemistry Reviews 19: 1199-1209. https://doi.org/10.1007/s11101-01909629-9

Tiko, G.H., Adamou, R., Amoussa, A.M.O., Medjigbodo, A.A., Sanni, A., Djogbénou, L.S. \& Lagnika, L. (2020). Antiplasmodial, antioxidant, hemolytic activities and acute toxicity of Costus afer Ker Gawl (Costaceae) used in malaria healing in Benin. Research Journal of Medicinal Plants 14: 24-34. https://doi.org/10.3923/rjmp.2020.24.34

Trott, O. \& Olson, A. (2010). Autodock vina: Improving the speed and accuracy of docking with a new scoring function, efficient optimization and multithreading. Journal of Computational Chemistry 31: 455-461. https://doi.org/ $10.1002 / j c c .21334$

Uddin, S.J., Bettadapura, J., Guillon, P., Darren Grice, I., Mahalingam, S. \& Tiralongo, E. (2013). In-vitro antiviral activity of a novel phthalic acid ester derivative isolated from the Bangladeshi mangrove fern Acrostichum aureum. Journal of Antivirals and Antiretrovirals 5: 139-144. https:// doi.org/10.4172/jaa.1000078

Uwah, A.F., Ewere, E.G. \& Ndem, J.I. (2015). Hypoglycemic and haematologic effects of crude stem juice of Costus afer on alloxan induced diabetic Wistar rats. American Journal of Ethnomedicine 2: 233-238.

Weng, L.M., Su, X. \& Wang, X.Q. (2021). Pain symptoms in patients with coronavirus disease (COVID-19): A literature review. Journal of Pain Research 14: 147-159. https://doi.org/ 10.2147/JPR.S269206.

World Health Organization (WHO) (2020). WHO supports scientifically-proven traditional medicine. https://www. afro.who.int/news/who-supports-scientificallyproventraditional-medicine. Accessed 28 May 2020.

Wu, C., Liu, Y., Yang, Y., Zhang, P., Zhong, W., Wang, Y., Wang, Q., Xu, Y., Li, M., Li, X. et al. (2020). Analysis of therapeutic targets for SARS-CoV-2 and discovery of potential drugs by computational methods. Acta Pharmaceutica Sinica $B$. 10: 766-788. https://doi.org/10.1016/j.apsb.2020.02.008

Yao, T.T., Qian, J.D., Zhu, W.Y., Wang, Y. \& Wang, G.Q. (2020). A systematic review of lopinavir therapy for SARS coronavirus and MERS coronavirus - A possible reference for coronavirus disease-19 treatment option. Journal of Medical Virology. 92: 556-563. https://doi.org/ 10.1002/ jmv. 25729

Yi, C., Sun, X., Ye, J., Ding, L., Liu, M., Yang, Z., Lu, X., Zhang, Y., $\mathrm{Ma}, \mathrm{L} ., \mathrm{Gu}, \mathrm{W}$. et al. (2020). Key residues of the receptor binding motif in the spike protein of SARS-CoV-2 that interact with ACE2 and neutralizing antibodies. Cellular \& Molecular Immunology 17: 621-630. https://doi.org/10.1038/ s41423-020-0458-z 
Zhang, L., Lin, D., Sun, X., Curth, U., Drosten, C., Sauerhering, L., Becker, S., Rox, K. \& Hilgenfeld, R. (2020). Crystal structure of SARS-CoV-2 main protease provides a basis for design of improved alpha-ketoamide inhibitors. Science 368: 409412. https://doi.org/10.1126/science.abb3405

Zhang, M.Q. \& Wilkinson, B. (2007). Drug discovery beyond the 'rule-of-five'. Current Opinion in Biotechnology 18: 478488. https://doi.org/10.1016/j.copbio.2007.10.005
Zhavoronkov, A., Aladinskiy, V., Zhebrak, A., Zagribelnyy, B., Terentiev, V., Bezrukov, D.S., Polykovskiy, D., Shayakhmetov, R., Filimonov, A., Orekhov, P. et al. (2020). Potential COVID19 3C-like protease inhibitors designed using generative deep learning approaches. ChemRxiv [Preprint]. https:// doi.org/10.13140/RG.2.2.29899.54569 